Kansas State University Libraries

New Prairie Press

\title{
A SPATIAL VIEW OF THE NEGATIVE BINOMIAL PARAMETER $k$ WHEN DESCRIBING INSECT POPULATIONS
}

Linda J. Young

Jerry $\mathrm{H}$. Young

Follow this and additional works at: https://newprairiepress.org/agstatconference

Part of the Agriculture Commons, and the Applied Statistics Commons

\section{(c) (1) $\Theta(9$}

This work is licensed under a Creative Commons Attribution-Noncommercial-No Derivative Works 4.0 License.

\section{Recommended Citation}

Young, Linda J. and Young, Jerry H. (1990). "A SPATIAL VIEW OF THE NEGATIVE BINOMIAL PARAMETER k WHEN DESCRIBING INSECT POPULATIONS," Conference on Applied Statistics in Agriculture.

https://doi.org/10.4148/2475-7772.1428

This is brought to you for free and open access by the Conferences at New Prairie Press. It has been accepted for inclusion in Conference on Applied Statistics in Agriculture by an authorized administrator of New Prairie Press. For more information, please contact cads@k-state.edu. 


\title{
A SPATIAL VIEW OF THE NEGATIVE BINOMIAL PARAMETER $\mathrm{k}$ WHEN DESCRIBING INSECT POPULATIONS
}

\author{
Linda J. Young ${ }^{1}$ and Jerry H. Young ${ }^{2}$ \\ ${ }^{1}$ Department of Biometry, University of Nebraska-Lincoln \\ ${ }^{2}$ Department of Entomology, Oklahoma State University
}

\begin{abstract}
Measures of aggregation as applied to insect populations are reviewed. When these measures indicate strong aggregation, an aggregated spatial pattern is often assumed. The literature noting that the measure of aggregation does not necessarily indicate spatial aggregation, or the lack of it, is reviewed. Field data from four insect species are presented. In each case, the measures of aggregation indicated strong aggregation, but the spatial pattern was not significantly different from random.
\end{abstract}

\section{INTRODUCTION}

The data collected in many entomological studies are composed of insect counts. Determining the distribution of these counts and the biological reasons that a particular distribution fits well is of primary interest. In practice, this process begins by viewing the relationship in estimated mean and variance. If the estimates of mean and variance are approximately equal, the Poisson is the first distribution considered. The Poisson is referred to as the random distribution in the entomological, and much of the biological, literature. This follows naturally from the fact that if each insect is equally likely to choose any minor habitat within the system and if this selection is independent of the choice made by every other insect, the Poisson distribution is the limiting distribution if the sample unit is the minor habitat. However, the Poisson is rarely observed in nature. Efforts to explain this departure from "randomness" has centered on heterogeneity of the environment and insect behavior such as food-gathering traits or mating behavior.

The binomial distribution is employed if the estimate of the sample mean is less than that of the sample variance. While this often occurs when doing presence-absence sampling, it is rare when working with insect counts.

The estimate of the variance exceeds that of the mean for most sets of entomological data. The negative binomial (NBD) distribution has historically fit many of these data sets. Since the mean is usually of interest, Anscombe's (1949) parameterization has become almost standard. If we let $\mathrm{X}$ represent the number of insects in a sample unit, which we will take to be the minor habitat of the insect, then the probability of observing $\mathrm{X}=\mathrm{x}$ is

$$
P(X=x)=\left(\begin{array}{c}
k+x-1 \\
k-1
\end{array}\right)\left(\frac{k}{\mu+k}\right)^{k}\left(\frac{\mu}{\mu+k}\right)^{x}, x=0,1,2, \ldots .
$$

The mean is $\mu$ and the variance is $\mu+\mu^{2} / \mathrm{k}$. The biological meaning of the mean is evident, but the interpretation of $\mathrm{k}$ has been more elusive. 


\section{AGGREGATION VS. SPATIAL PATTERN}

The negative binomial parameter $\mathrm{k}$ is referred to as the aggregation parameter. As $\mathrm{k}$ decreases, the population is said to become more aggregated, or clumped. If $\mathrm{k} \rightarrow \infty$, the Poisson distribution results. Thus increases in $\mathrm{k}$ are used to indicate a movement toward "randomness". Waters (1959) illustrated the effect of k using 100 insects and a sample size of 25. Four different arrangements of the insects within the sample units were used to illustrate that decreases in $\mathrm{k}$ are associated with increased aggregation of the insects within the sample units (see Figure 1).

Other methods of measuring aggregation have been proposed (see Nicot, Rouse, and Yandell, 1984). Table 1 illustrates that in each case, decreasing values of $\mathrm{k}$ are associated with increasing measures of aggregation. Since the location of each observation is not used in the determination of $\mathrm{k}$ or the computation of the measures of aggregation, no basis exists for inferences relating these quantities to the spatial structure of the insects within the system. However, it is commonly assumed that decreasing values of $\mathrm{k}$ and increasing measures of aggregation are associated with increased spatial aggregation. Southwood (1979) expresses this view when he says, "The dispersion of a population, the description of the pattern of the distribution or disposition of the animals in space, is of considerable ecological significance." This statement is followed by a discussion of the role of the binomial, Poisson, and negative binomial distributions in describing these spatial patterns.

Patil and Stiteler (1974) pointed out that a Poisson distribution does not necessarily imply a random spatial pattern. Suppose that the number of insects within a sample unit follows a binomial distribution with parameters $n$ and $p$. Further assume that due to heterogeneity in the environment, $n$ varies over the region according to the Poisson distribution. Then the numerical distribution of the insects would be Poisson, but the spatial structure would reflect the heterogeneity of the ecosystem and would not be random unless the heterogeneity occurred randomly.

Nicot, Rouse, and Yandell (1984) showed that both the Poisson and the NBD could be associated with regular, random, or aggregated spatial patterns. Six hypothetical fields were analyzed for spatial patterns. Three of these were formed to provide a good fit to the Poisson distribution. In all three fields, the value of the variance-to-mean ratio was 1.01 , but each had a very different spatial structure. Although the traditional measures of aggregation were unable to distinguish among the three spatial patterns, Moran's (1950) I, a coefficient of spatial autocorrelation, did show the spatial structure ranged from regular to random to aggregated. The negative binomial distribution fit the frequency distribution of the other three fields. For each of these, the variance-to-mean ratio was 2.37 , indicating strong aggregation. However, Moran's I again correctly depicted the change in spatial structure as it changed from regular to random to aggregated.

Insight into the relationship, if any, in measures of aggregation and spatial structure may be gained by contrasting true contagion and apparent contagion processes (see Gurland, 1959). A true contagion, or generalized Poisson, process would describe a pattern in which the insects occur in small clusters that are randomly scattered throughout the system. Since 
aggregation occurs on a scale smaller than the sampling unit, the observed spatial structure would be random. An apparent contagion, or compound Poisson, process occurs when insects are randomly scattered within each sampling unit, but the average number of insects within a sample is a variable that takes different values from sample to sample. Here aggregation is present on a larger scale than the sampling unit. If the average number of insects within a sample is spatially influenced, then the spatial structure will not be random.

Numerous models can give rise to the negative binomial distribution. As indicated above, some would imply an aggregated spatial structure, but others would not. An investigation was conducted to determine whether or not numerical distributions that are considered highly aggregated are necessarily indicative of an aggregated spatial pattern for some insects.

\section{EXPERIMENTAL RESULTS}

Oat bird-cherry aphids (Rhopalosiphum padi (L.)) on seedling oats and Collops spp., convergent lady beetles (Hippodamia convergens Guerin Meneville), and cotton fleahoppers (Pseudatomoscelis seriatus Reuter) on cotton were each sampled by two methods. First, a random sample was taken to obtain good estimates of the underlying numerical distribution. Then observations were taken down a row to provide a measure of the spatial aggregation that may be present.

Oat bird-cherry aphids were collected from a field of spring oats in Noble County, Oklahoma, which is in the north central part of the state, on March 31, 1986 (Sinclair 1986). A sample of $\mathrm{n}=584$ plants produced estimates of the mean $(0.345)$, variance $(0.527), \mathrm{k}$ (0.654), and the variance-to-mean ratio (1.527). These would indicate the presence of strong aggregation. To evaluate spatial pattern, twelve contiguous rows were sampled. Observations consisted of counting the number of insects on each plant and recording the data in order of the plant's occurrence in the row. A test for the homogeneity of the rows supported the assumption of homogeneity within the field. Bartlett's test of white noise based on the periodogram and the Portmanteau test of white noise predicated on the correlogram were conducted. In no case could the null hypothesis of white noise be rejected. In Figure 2, the correlogram and periodogram for one row are presented with $95 \%$ simultaneous confidence bands under the hypothesis of white noise. The correlogram is a graph of the sample autocorrelation function versus the lag $\mathrm{k}=0,1,2, \ldots$. The correlogram may be used to visually assess the order of the series. The sample cumulative periodogram is a plot of the sample spectral distribution function corresponding to the sample spectral density function evaluated at the natural frequencies $\omega_{\mathrm{k}}=(\mathrm{k}-1) / \mathrm{n}, \mathrm{k}=$ $1, \ldots,[n / 2]+1$, where $n$ is the length of the series. In Figure 2, as in all subsequent figures, the row showing the greatest disparity with white noise is presented.

A census of insects on a quarter acre of cotton was taken July 9, 1974, near Tipton, which is in Tillman County in southwestern Oklahoma (reported in Hill, et al., 1975). The number of convergent lady beetles and Collops spp. were recorded for each plant. A random sample of 120 was drawn. For the convergent lady beetle, estimates were obtained for the mean (2.542), variance (4.932), $\mathrm{k}$ (2.703), and the variance-to-mean ratio (1.94). 
Estimates of the mean (2.958), variance (4.958), $\mathrm{k}$ (4.376), and variance-to-mean ratio (1.676) were also computed for the Collops. Forty observations were taken down each of three rows. The assumption of homogeneity could not be rejected. While the numerical distribution would indicate aggregation, Bartlett's and Portmanteau's tests for white noise did not produce evidence of an aggregated spatial pattern (see Figures 3 and 4).

Cotton fleahoppers were sampled in Grady County, in central Oklahoma, during July and August of 1986 and 1987. On August 4, 1986, a sample of size 150 produced estimates of the mean (0.687), variance (1.129), $\mathrm{k}$ (1.065), and the variance-to-mean ratio (1.643) that would indicate strong aggregation. Fifty observations were made down each of three rows, and the hypothesis of white noise could not be rejected in any case (see Figure 5). In addition, the same rows were sampled on 7 days in a two-week period during 1986 and on four days in a 8-day period during 1987. No correlation could be found on the same row on a given day or on the same plant over the sampling period.

The examples given above support the idea that the measures of aggregation which are currently widely used do not provide good measures of the spatial structure within a system. A negative binomial distribution with a small value of $\mathrm{k}$ does not necessarily imply an aggregated spatial pattern. Young and Willson (1987) show that the interaction of insects with other species members may produce the NBD. In this case, the heterogeneity is produced by the insects. A plant that is occupied is more attractive to an insect than an unoccupied plant. In such cases, the aggregation is occurring on a scale smaller than the sample unit. However, this work should not be construed to imply that aggregated insect spatial patterns do not occur because they do (see Schotzko and O'Keefe, 1989, for an example). To draw accurate inferences about the spatial structure within a system, a method that utilizes the location of the samples relative to each other must be employed.

\section{SUMMARY}

Measures of aggregation such as the negative binomial parameter $\mathrm{k}$, Fisher's varianceto-mean ratio, David and Moore's index of clumping, Lloyd's index of mean crowding, and Lloyd's index of patchiness are often used to draw inferences relating to the spatial structure of the system. Since the relative locations of the observations are not used in the computation of any of the indices, no foundation exists for concluding that a high measure of aggregation is associated with an aggregated spatial pattern. Several insect species were sampled. Initial random samples produced estimates indicating the presence of strong aggregation. However, an analysis of spatial pattern did not lead to the rejection of the hypothesis of white noise in any case. While some insects do have aggregated spatial patterns, aggregation represented in the numerical distribution does not necessarily imply that the insects are aggregated spatially.

\section{ACKNOWLEDGMENTS}

A major portion of this work was completed while the first author was a member of the Department of Statisitics, Oklahoma State University. 


\section{REFERENCES}

Gurland, J. 1959. Some applications of the negative binomial and other contagious distributions. Am. J. Public Health 49: 1388-1399.

Hill, B.G., R.W. McNew, J.H. Young and W.E. Ruth. 1975. The effects of sampling-unit size in some southwestern Oklahoma cotton insects. Environ. Entomol. 4: 491-494.

Nicot, P.C., Rouse, D.I., and Yandell, B.S. 1984. Comparison of statistical methods for studying spatial patterns of soilborne plant pathogens in the field. Am. Phyt. Soc. 74: 1399-1402.

Patil, G.P. and Stiteler, W.M. 1974. Concepts of aggregation and their quantification: A critical review with some new results and application. Res. Pop. Ecol. 15: 238-254.

Pielou, E.C. 1977. Mathematical Ecology. John Wiley and Sons, Inc.: New York. 385 pp.

Schotzko, D.J. and O'Keefe, L.E. 1989. Geostatistical description of the spatial distribution of Lygus hesperus (Heteroptera: Miridae) in lentils. J. Econ. Entomol. 82: 1277-1288.

Sinclair, M.D. 1986. A new look at insect aggregation in agroecosystems. M.S. report. Oklahoma State University, Stillwater, OK.

Southwood, T.R.E. Ecological Methods. Chapman and Hall: London.

Waters, W.E. 1959. A quantitative measure of aggregation in insects. J. Econ. Entomol. 52: $1180-1184$.

Young, J.H. and Willson, L.J. 1987. Use of Bose-Einstein statistics in population dynamics models of arthropods. Ecological Modelling 36: 89-99. 
Table 1.

Measures of Aggregation

\begin{tabular}{|c|c|c|}
\hline Measure & Poisson & NBD \\
\hline $\begin{array}{c}\text { Fisher's Variance-to- } \\
\text { Mean Ratio }\end{array}$ & 1 & $1+\mu / \mathrm{k}$ \\
\hline $\begin{array}{c}\text { David and Moore's } \\
\text { Index of Clumping } \\
\left(\sigma^{2} / \mu-1\right)\end{array}$ & 0 & $\mu / \mathrm{k}$ \\
\hline $\begin{array}{c}\text { Lloyd's Index of } \\
\text { Mean Crowding } \\
\left(\mathrm{m}^{*}=\mu+\sigma^{2} / \mu-1\right)\end{array}$ & $\mu$ & $1+1 / \mathrm{k}$ \\
\hline $\begin{array}{c}\text { Lloyd's Index of } \\
\text { Patchiness }\left(\mathrm{m}^{*} / \mu\right)\end{array}$ & 1 & \\
\hline
\end{tabular}

Figure 1.

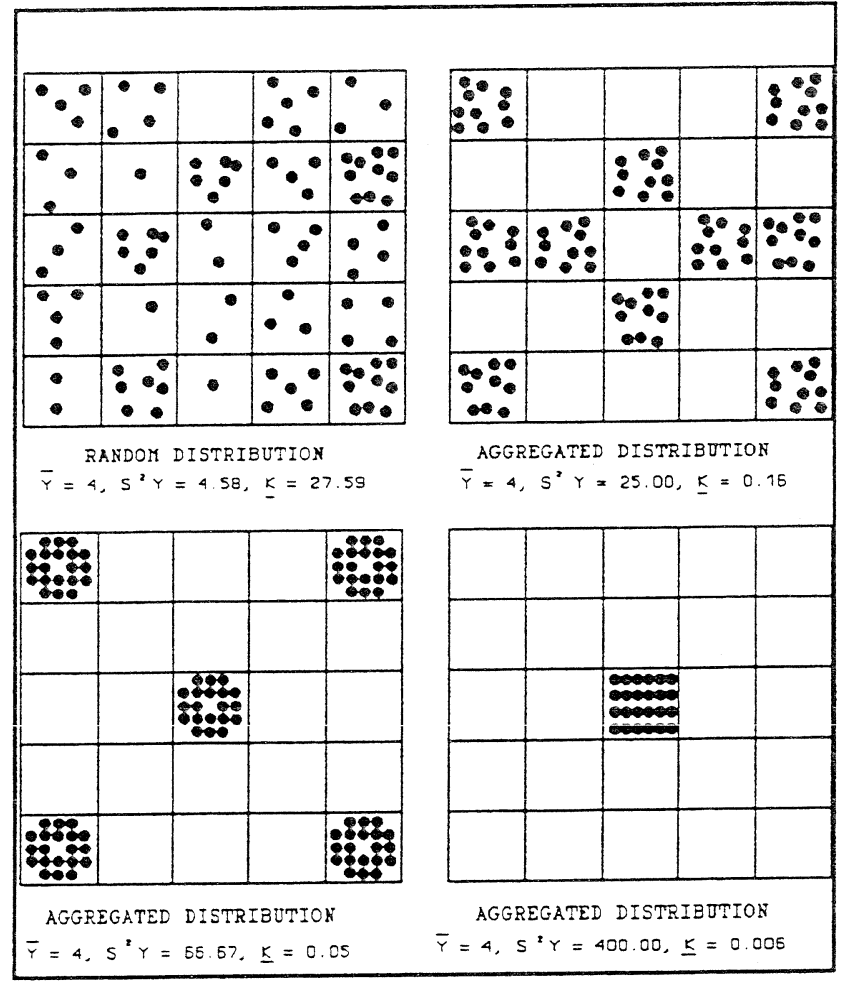


Figure 2.
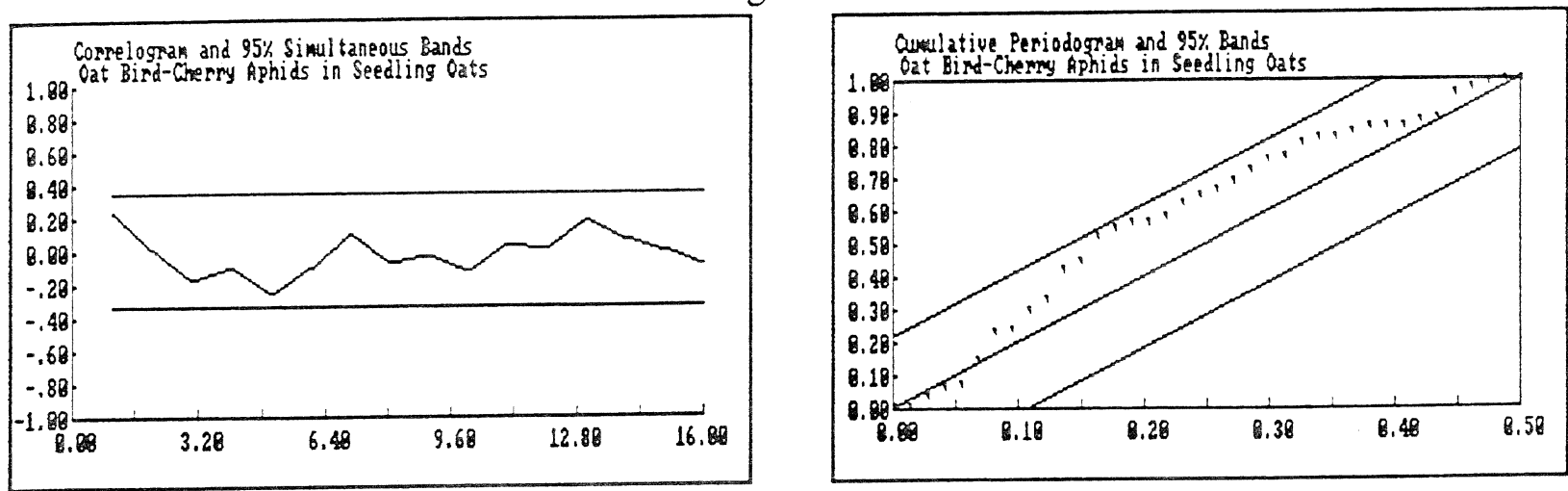

Figure 3.
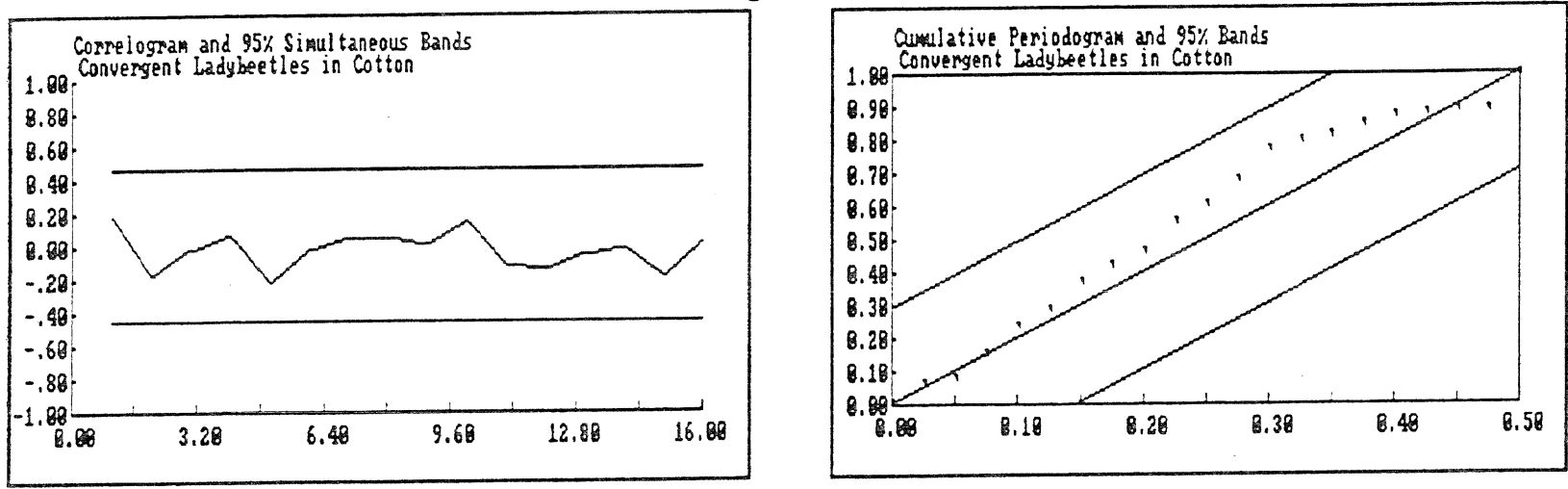

Figure 4.
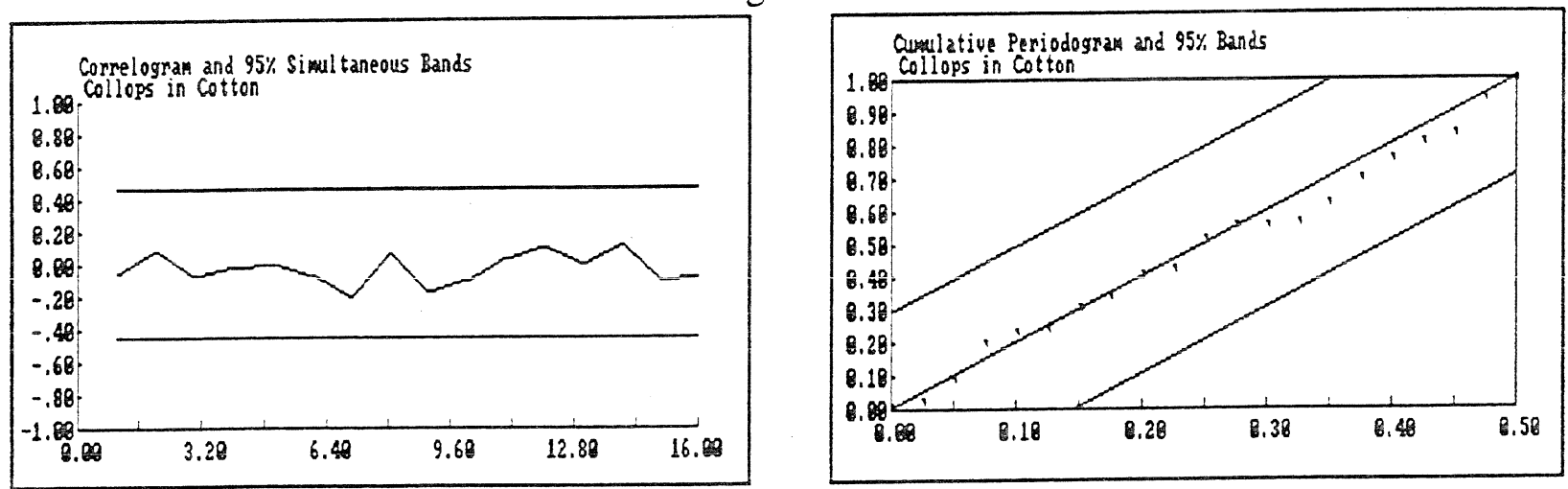
Figure 5.
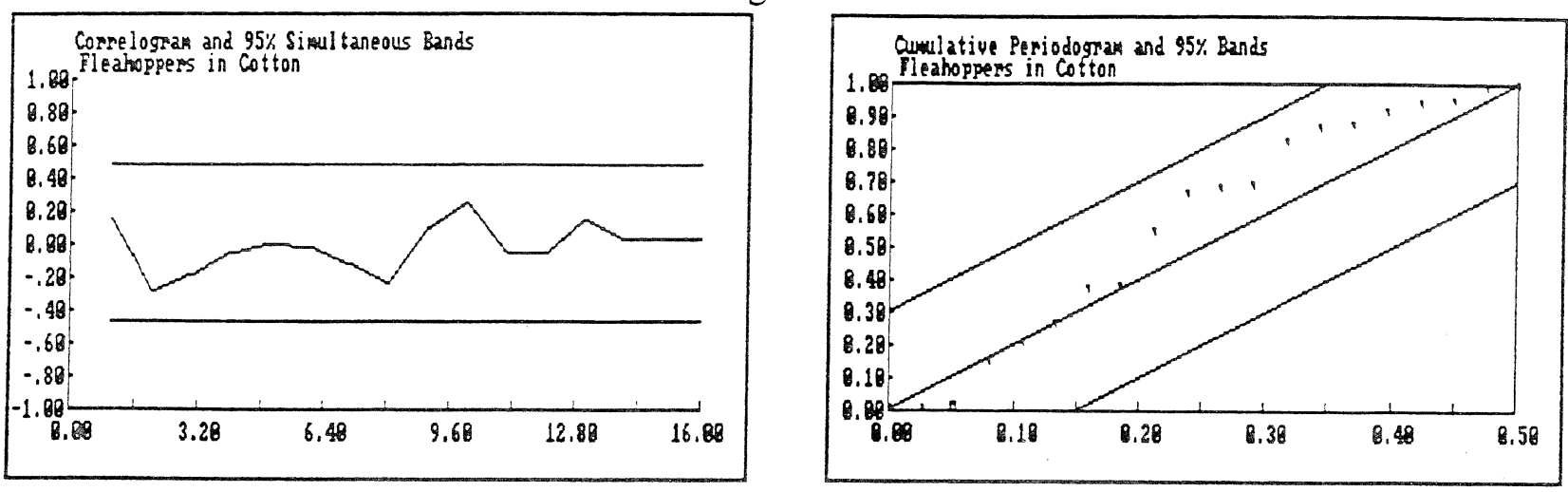